\title{
Entre el "desierto" y el productivismo: un recorrido por la historia de las interpretaciones sobre la naturaleza en la Patagonia Central de Argentina
}

Between the "desert" and productivism: a trajectory through the interpretations about nature in Argentina's Central Patagonia

\author{
Mercedes Ejarque* \\ [mercedes.ejarque@gmail.com]
}

DOI: $10.5935 / 2237-2717.20160014$

Cita sugerida: Ejarque, Mercedes. "Entre el 'desierto' y el productivismo: un recorrido por la historia de las interpretaciones sobre la naturaleza en la Patagonia Central de Argentina." HALAC VI, no. 2 (Diciembre 2016): 246-262.

\begin{abstract}
RESUMEN
La Ecología Política Latinoamericana y otras corrientes de los estudios ambientales han sostenido la existencia de múltiples relaciones entre la sociedad y la naturaleza y formas de interpretarlas por parte de los agentes sociales. Con este punto de partida, este artículo propone un recorrido por las interpretaciones y valoraciones sobre la naturaleza en las tierras secas de Chubut, una provincia de la Patagonia Central de Argentina. A lo largo de su historia, la naturaleza en esta región fue considerada como hostil, indómita y, por último, armoniosa con el hombre. Detrás de estas interpretaciones se observa un lenguaje de valoración predominante de tipo "productivista", centrado en entender cómo la naturaleza contribuía o frenaba la producción ganadera, principal actividad económica de la zona. Así, otros lenguajes de valoración de la naturaleza quedaban subsumidas y se fomentaron prácticas que llevaron al actual deterioro de las tierras secas del área.
\end{abstract}

\section{Palavras claves}

Naturaleza, Historia Ambiental, Tierras Secas, Lenguaje de Valoración.

\section{ABSTRACt}

Latin-American Political Ecology and other theories from environmental studies have stated that there are multiple relations between society and nature and several ways in which social agents interpretate those relations. With this starting point, this article proposes a trace through the interpretations and valuations about the nature in the drylands located in Chubut, a province in Central Patagonia of Argentina. Through its history, nature in this region has been considered as hostile, indomitable and lastly, harmonious with humans. Behind these interpretations it can be found a valuation language centered in productivity: it focused on understanding how nature contributed or restrained livestock production, which is the main economic activity in the area. Thus other valuation languages about nature were subsumed and practices that led to the actual state of degradation of the drylands in this area were promoted.

\section{KEYWORDS}

Nature, Environmental History, Dry Lands, Valuation Languages.

\footnotetext{
* Doctora en Ciencias Sociales. Instituto de Investigaciones Gino Germani, Facultad de Ciencias Sociales, Universidad de Buenos Aires (UBA). Becaria del Consejo Nacional de Investigaciones Científicas y Técnicas (CONICET). Argentina.
} 


\section{Introducción}

En los estudios sociales, si bien la relación sociedad- naturaleza tiene una clara historia de reflexión, problematización, intentos de caracterización e inclusive desarrollo de modos de investigación, desde los inicios de la Modernidad fue claro el predominio de una concepción dualista de las relaciones entre el hombre y la naturaleza. ${ }^{1}$ En la filosofía moderna, la naturaleza se volvía algo ajeno a la sociedad y de mero carácter instrumental. Esta escisión provocó que la naturaleza se dejara de lado en los estudios sociales hasta que, entre las décadas de 1960 y 1970, frente a la presencia de problemas ecológicos de gran envergadura o globales, se reconsideraron las influencias mutuas entre la sociedad y la naturaleza para poder dar cuenta de la complejidad de la realidad.

En las últimas décadas, estos análisis han sido enriquecidos de dos maneras. Por un lado, el desarrollo de la historia ambiental preocupada no por un determinismo natural en la historia social, sino en reconstruir el proceso de mercantilización de la naturaleza que atravesaron las diferentes sociedades en esa interrelación con la naturaleza, dándole materialidad a la historia. ${ }^{2}$ En ese plano la naturaleza puede volverse "recurso" sólo cuando una sociedad, en un momento histórico determinado, le otorga ese valor en función de un cierto objetivo.

Por otro lado, la ecología política, la sociología ambiental y otras vertientes y disciplinas dentro de las ciencias sociales y humanas han evidenciado la existencia de narrativas, percepciones, representaciones o imaginarios sociales sobre la naturaleza. La diversidad de interpretaciones existentes en un determinado espacio son expresiones de las relaciones de poder que existe en la apropiación, control y definición de la naturaleza por parte de distintos agentes sociales, ${ }^{3}$ en un entramado que también sugiere cómo se relacionan, ubican, clasifican e inclusive conceptualizan los humanos. ${ }^{4}$ Estas relaciones son las que establecen las posibilidades de imponer un discurso hegemónico sobre la naturaleza y su utilización.

Esta investigación se enmarca dentro de este campo de estudio, buscando aportar al proceso de comprensión de las relaciones entre la sociedad y la naturaleza en las tierras secas, ${ }^{5}$ a través de la introducción en los análisis de las interpretaciones y las prácticas sobre la naturaleza que los agentes sociales en el territorio realizan. Así, se incorporan los lenguajes de valoración, la dimensión simbólica involucrada en el uso, apropiàción y consumo de la naturaleza ${ }^{6}$ que se ponen en juego en los procesos vinculados a la mercantilización de los componentes biofísicos que atraviesa cada sociedad y que va modificando su interrelación con el entorno. ${ }^{7}$ Estos lenguajes de valoración se ponen en

\footnotetext{
1 Véase: William Catton y Riley Dunlap, "Environmental Sociology: A New Paradigm," The American Sociologist 13, n. 1 (1978): 41-49; Enrique Leff, “La ecología política en América Latina. Un campo en construcción”, en Los tormentos de la materia. Aportes para una ecología política latinoamericana, ed. Héctor Alimonda (Buenos Aires: CLACSO, 2006), 21-40.

${ }^{2}$ Héctor Alimonda, "La colonialidad de la naturaleza. Una aproximación a la Ecología Política Latinoamericana", en La naturaleza colonizada. Ecología política y minería en América Latina, ed. Héctor Alimonda (Buenos Aires: CLACSO, 2011), 21-60.

${ }^{3}$ Germán Palacio, "Breve guía de introducción a la Ecología Política (Ecopol): orígenes, inspiradores, aportes y temas de actualidad", Gestión y Ambiente 9, no. 3 (2006): 143-56.

4 Leticia Saldi y Lucrecia Wagner, "Aportes antropológicos a la Historia Ambiental en contextos y estudios latinoamericanos", Revista Latino-Americana de Historia 2, no. 8 (2013): 8-30.

${ }^{5}$ Éstas incluyen todas las tierras donde el clima es clasificado como seco, es decir, que se incluye el hiperárido, árido, semiárido y subhúmedo seco, según el índice de aridez utilizado por la Convención Internacional de Lucha contra la Desertificación en: Elena Abraham, María Corso, y Patricia Macagno, "Tierras secas y desertificación en Argentina", en Evaluación de la desertificación en Argentina. Resultados del Proyecto LADA/ FAO, FAO (Buenos Aires, 2011).

${ }^{6}$ Joan Martínez Alier, El ecologismo de los pobres (Barcelona: Icaria- Antrazyt, 2004).

7 Alimonda, "La colonialidad de la naturaleza. Una aproximación a la Ecología Política Latinoamericana".
} 
evidencia más claramente en los momentos de conflictos ambientales, en las confrontaciones abiertas, ${ }^{8}$ pero también se disputan y algunos resultan mejor posicionados que otros en instancias donde hay interpretaciones diversas frente a problemas ambientales aunque no se produzcan en instancias de disputas discursivas.

En este artículo se analizan las diferentes interpretaciones sobre la naturaleza presentes en las tierras secas de Chubut (en la Patagonia Central de Argentina) y los modos en que los cambios en estas interpretaciones modificaron las prácticas sociales en torno a la ganadería ovina y el uso de esa naturaleza. En el Mapa 1 se ilustra el área de estudio, en el que se han tomado dos regiones en conjunto: las Comarcas Meseta Central y Valle Inferior del Río Chubut, cuyas economías son altamente dependientes de la producción ganadera ovina y donde un problema ambiental de largo plazo, la desertificación de sus tierras ${ }^{9}$ afecta a más del $90 \%$ de su superficie $^{10}$ y ha contribuido a la crisis de la ganadería. Entre ellas, sostienen vínculos productivos, comerciales y políticos respecto a la desertificación y la actividad lanera que motivan su análisis en conjunto (mientras la Meseta concentra principalmente la actividad primaria, en la zona del Valle se encuentra la sede del poder político provincial con los principales organismos e instituciones científicas y tecnológicas que entienden en el tema, es una zona de engorde para la producción de carne ovina e incluye el polo lanero al que se destina la mayor parte de la lana obtenida en la zona).

Este recorrido histórico presenta un desafío para su desarrollo que proviene de la ausencia de información sobre ciertos períodos, regiones, y procesos que se encuentran menos estudiados. La historiografía chubutense en los últimos años recién ha comenzado a profundizar en la historia social, natural y productiva de la provincia. Por ello, se han utilizado tanto estudios específicos de la zona, como otros que abordaron la región patagónica en general o alguna de sus jurisdicciones, aclarando en estos casos el lugar de referencia. También se trabajó con fuentes documentales: el diario Esquel (fundado en 1925, recogía noticias locales, provinciales y nacionales) y la revista Argentina Austral (de tirada patagónica, editada por la Sociedad Anónima Importadora y Exportadora de la Patagonia y que presentaba noticias sobre la ganadería y las opiniones de los grandes productores). Para el análisis de la actualidad se ha entrevistado a técnicos, productores, contratistas de mano de obra y servicios, trabajadores y personal de barracas vinculados a la producción de lana de Chubut entre 2008 y 2014.

\footnotetext{
${ }^{8}$ Ronny J. Viales Hurtado et al., "Lenguajes de valoración y percepciones de la comunidad ante el impacto de la mina Bellavista. 2007-2012", Historia Ambiental Latinoamericana y Caribeña III, no. 2 (2014): 378-420.

${ }^{9} \mathrm{La}$ desertificación de la tierra es el nombre que se ha consensuado científicamente para definir al proceso de "degradación de las tierras de zonas áridas, semiáridas y subhúmedas secas, resultante de diversos factores, tales como las variaciones climáticas y las actividades humanas". Convención de las Naciones Unidas de Lucha contra la Desertificación (Paris: Organización de Naciones Unidas, 1994), art. № 1 inciso A.

10 INTA y GTZ, "Proyecto Integrado: Prevención y control de la desertificación para el desarrollo sustentable de la Patagonia" (Centro Regional Patagonia Sur y Pāagonia Norte, INTA y Sociedad Alemana para la Cooperación Técnica, 1994).
} 
Mapa 1: Área de estudio: Comarcas Meseta Central y Valle Inferior del Río Chubut, Chubut (Argentina).

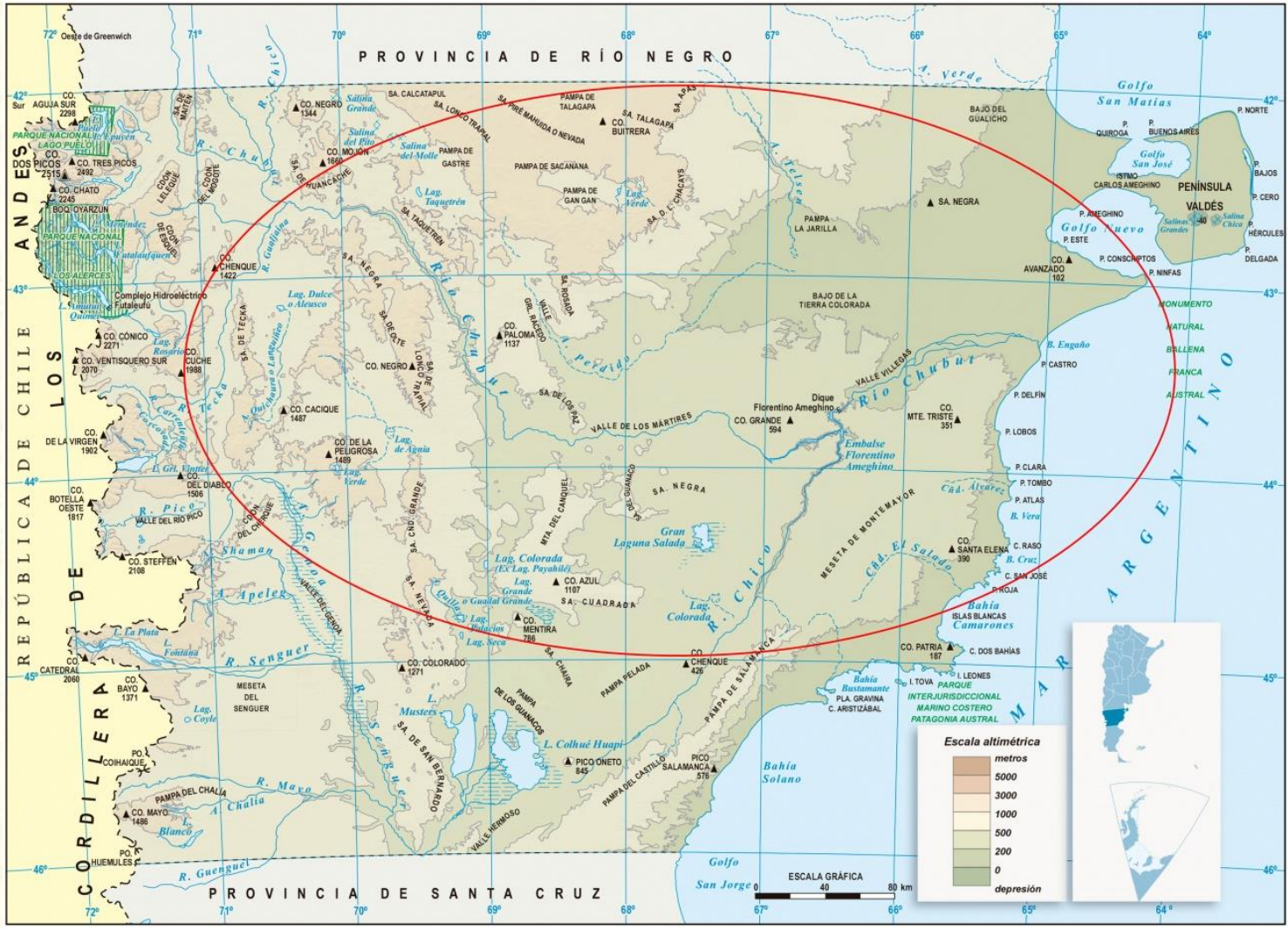

Fuente: Elaboración propia.

En el siguiente apartado se describen las distintas interpretaciones de la naturaleza y las prácticas en torno a ella, que predominaron en cada momento histórico de la historia reciente de las tierras secas chubutenses. Se observa cómo hay sentidos que se vuelven dominantes en ciertos momentos, y otros que se encuentran subsumidos. Asimismo se reconstruyen las propuestas de acción sobre la naturaleza y sus cambios, mostrando cómo éstas fueron valorizadas de forma diferente según quiénes las llevaron a cabo. Luego se analiza la situación actual en la cual resulta más evidente la heterogeneidad de interpretaciones respecto a la naturaleza. Esto genera el sostenimiento de prácticas que contribuyen al deterioro y la implementación de otras que buscan prevenir, mitigar o revertir el "daño" producido y la pérdida de capacidad productiva de la naturaleza árida. Por último, como en todo proceso; existen continuidades, persistencias de interpretaciones y prácticas entre distintos momentos y por eso, se pone en evidencia la existencia de un lenguaje de valoración "productivista", focalizado en la actividad ovina para la obtención de lana, que condiciona la adopción de otras prácticas que podrían generar la reducción del deterioro de las tierras secas.

\section{Interpretaciones sobre la naturaleza en la historia de las tierras secas chubutenses}

Este apartado presenta, a través del análisis de las fuentes disponibles, un recorrido por las interpretaciones sobre la naturaleza que estuvieron presentes y predominaron en distintos momentos históricos en el área de estudio localizado en la Patagonia Argentina. El primer momento se caracterizó por la definición de la naturaleza como "hostil", luego como 
"indómita" y en el último tramo del siglo XX, por la búsqueda de lograr una armonía entre la naturaleza y la sociedad. Como se verá a continuación, estas interpretaciones se relacionaban con prácticas específicas en la zona y con grupos determinados, que imponían entonces visiones predominantes, subsumiendo otras que también se encontraban presentes y que eran desarrolladas por otros agentes sociales.

\section{Naturaleza hostil}

En las tierras secas de Chubut, el uso de la naturaleza ha estado históricamente asociado a la ganadería. Los pueblos originarios, primero subsistieron de la caza y la recolección; y una vez asentados, seguían rutas perfectamente determinadas para la búsqueda de los animales.11 Este antecedente de la transhumancia como método de manejo de la ganadería, implicaba recorrer anualmente diversos territorios de acuerdo a sus posibilidades productivas $^{12}$ aprovechando lo que naturaleza proveía en cada lugar y momento del año.

Ese fue el manejo ganàdero en estos territorios que se encontraban aislados y poco considerados en la organización política nacional hasta mediados del siglo XIX, cuando llegaron los primeros intentos "colonizadores" de la zona. Junto con ellos, en un contexto donde la Patagonia comenzaba a ser de interés para ciertos grupos dominantes y para los gobernantes nacionales, este territorio fue objeto de expediciones de científicos y viajeros, en las cuales se buscaba, a través del conocimiento científico, legitimación para la dominación. En general recreaban la idea de un espacio "hostil" relacionado con la imagen de un "desierto", que servía de sustento o justificaba el fracaso de muchos intentos colonizadores. Esta imagen no sólo remitía a su supuesto carácter despoblado, sino por sus atributos naturales. Según Baeza, esta caracterización fue parte del mito fundacional de la Patagonia, ${ }^{13}$ y "una construcción legitimadora de una cierta política de concentración de recursos y posibilidades". ${ }^{14}$ Prontamente la idea del "desierto" fue combinada con el descubrimiento de potencialidades económicas, inclusive en las tierras secas las cuales se consideraban que podían ser explotadas para la ganadería ovina y así poder desplazarla de la zona pampeana. Esto motivó el interés en explotar los recursos naturales, ${ }^{15}$ para ampliar las fronteras y construir el territorio nacional. ${ }^{16}$ En este contexto, la zona de tierras secas quedó signada por la interpretación de que tenía recursos "limitados" sólo "útiles para la ganadería ovina: ${ }^{17}$

\footnotetext{
${ }^{11}$ Susana Bandieri, Historia de la Patagonia (Buenos Aires: Sudamericana, 2009).

${ }^{12}$ Mónica Bendini, Pedro Tsakoumagkos, y Cristina Nogués, "Los crianceros transhumantes en Neuquén", en Crianceros y chacareros en la Patagonia., de Mónica Bendini y C Alemany, Cuaderno GESA 5 (Buenos Aires: La Colmena, 2005).

${ }^{13}$ Brígida Baeza, Fronteras e identidades en Patagonia Central (1885-2007) (Rosario: Prohistoria Editores, 2009).

14 Santiago Conti y Paula Núñez, "La violencia "del silencio, las mujeres de la estepa", Polémicas Feministas. Área Feminismos, Género y Sexualidades-FemGeS, n. 2 (2015): 69-77, 71.

${ }^{15}$ María Teresa Luiz y Mónika Schillat, "De la virtualidad de las fronteras políticas a la realidad de la frontera en el imaginario. Patagonia Meridional y Tierra del Fuego, siglos XVI-XX", en Cruzando la cordillera. La frontera argentino-chilena como espacio social, de Susana Bandieri (Neuquén: Centro de Estudios de Historia Regional, Facultad de Humanidades, Universidad Nacional del Comahue, 2001).

${ }^{16}$ Baeza, Fronteras e identidades en Patagonia Central (1885-2007).

${ }^{17}$ Se establecía una comparación respecto a la cordillera y en los valles, donde se planteaban interpretaciones alineadas con la forma en que se caracterizó a América desde la época de la colonia: con presente de fuentes de recursos "inagotables". Para un desarrollo sobre los discursos sobre la naturaleza americana en su perspectiva histórica ver: Fernando Mires, El discurso de la naturaleza: ecología y política en América Latina (Buenos Aires: Espacios, 1990).
} 
Los inconvenientes del clima [...] sobre todo donde las precipitaciones pluviales son escasas, llevaron a creer, tras los primitivos ensayos, que la agricultura era impracticable. Las ovejas, en cambio, se criaban con algún aliciente a pesar del mucho frío, de la poca agua, el escaso pasto y el viento pertinaz. La naturaleza inducía a una rápida preferencia. ${ }^{18}$

Bajo esta impronta, las tierras secas de Chubut comenzaron hacia fines del siglo XIX a ser ocupadas masivamente por ovejas, con un crecimiento constante de la actividad. ${ }^{19}$ Los recién llegados a la zona primeros basaron sus prácticas productivas en la utilización de "campos abiertos" sin delimitación de la propiedad o lugar de uso de cada productor. Los "ovejeros" iban arreando los animales a través de los lugares con mayor disponibilidad de forraje y agua y con protección de arbustos, cerros o cañadones frente a los vientos. "Esta manera de trabajar, esta especie de transhumancia, permitía hacer un uso adecuado del forraje, manteniendo los animales en invierno en campos protegidos, como hemos dicho y trasladándolos en verano a zonas altas y pastosas". ${ }^{20}$ De esta manera, si bien habían sido criticadas en sus inicios las prácticas de los pueblos originarios, el método transhumante también fue aplicado por la población blanca.

Las interpretaciones de los expedicionarios de esa época mostraron una valoración diferencial a los usos de la naturaleza según la población que los realizaba. A modo de ejemplo, Sourrouille evidencia que para el explorador galés LIwid Ap Iwan (quien recorrió la Patagonia entre 1894 y 1895) el desmonte para la cría de ganado o la agricultura eran prácticas legítimas, mientras que se consideraba destructiva la utilización de fuegos intencionales de los campos para la caza que utilizaban algunos pueblos originarios. ${ }^{21}$ Lo mismo observó Bandieri respecto a al recorrido de Ramón Lista y del sacerdote salesiano José Fagnano en 1886 cuando mencionaron las cualidades productivas de la región para la cría del ganado ovino, sentando las bases para la ocupación blanca definitiva. ${ }^{22}$ Así se presentaba una valorización diferencial respecto a las prácticas de los pueblos originarios y la de los colonos, justificadas en sus aportes para el "desarrollo" regional. ${ }^{23}$

Con el incremento del poblamiento, tanto de personas como de ovejas, se produjeron luchas por esos "recursos limitados" que brindaba la naturaleza en las tierras secas (mallines, cañadones, manantiales o lagunas) y la decisión, con el aval del Estado, de cercar y alambrar las tierras, que habían sido asignadas individualmente y así evitar el acceso público a las zonas con mejores forrajes o agua. Según el agrónomo Rodríguez Romero, la distribución de esas tierras, con un trazado geométrico, no contempló en todos los casos el acceso a tierras bajas y altas ni otros factores hidrológicos, ecológicos o geográficos. Además, con el alambrado, las extensiones utilizadas por cada productor se reducían y eran ellos, en función de su conocimiento empírico, los que definían la cantidad de hacienda

\footnotetext{
18 Juan Lenzi, "La conquista del campo: epopeya de los ovejeros patagónicos", Argentina Austral Selección de artículos Tomo I, n. ${ }^{\circ} 316$ (1958): 462.

${ }^{19}$ Susana Aparicio, María Marcela Crovetto, y Mercedes Ejarque, "Las condiciones de trabajo de los asalariados en la esquila patagónica argentina", Mundo Agrario 13, n. ${ }^{\circ} 26$ (junio de 2013): 1-22.

${ }^{20}$ Miguel Rodríguez Romero, "Ganadería y erosión en Patagonia", Argentina Austral Selección de artículos Tomo I, n. ${ }^{\circ} 412$ (1966): 536-41, 531

${ }^{21}$ Marcos Sourrouille, "Estrategias agropecuarias, sustentabilidad y políticas públicas: una propuesta de historia ambiental para el noroeste del Chubut (1890-2010)", en VII Jornadas Interdisciplinarias de Estudios Agrarios y Agroindustriales (VII Jornadas Interdisciplinarias de Estudios Agrarios y Agroindustriales, Buenos Aires, 2011).

22 Susana Bandieri, "Ampliando las fronteras: la ocupación de la Patagonia", en Nueva Historia Argentina: El progreso, la modernización y sus límites (1880-1916), de Mirta Lobato (Buenos Aires: Sudamericana, 2000).

${ }^{23}$ Sourrouille, "Estrategias agropecuarias, sustentabilidad y políticas públicas: una propuesta de historia ambiental para el noroeste del Chubut (1890-2010)".
} 
soportable en el nuevo espacio alambrado. El paisaje patagónico que había sido caracterizado por "la pobreza del suelo, su sequedad y su frialdad" había impulsado el "monocultivo" ovino y el uso individual y restringido de los "escasos recursos". ${ }^{24}$

Consolidada la ocupación del territorio para la ganadería ovina, en las primeras décadas del siglo XX, se encuentran las primigenias menciones sobre el sobrepastoreo de los campos, ${ }^{25}$ pero se destaca la ausencia de acciones al respecto. Por ejemplo, según Bailey Willis, en 1914 el pastoreo se realizaba de manera "poco cuidadosa", recargando los campos y destruyendo los pastos. ${ }^{26}$ En sus notas sostenía que era preciso conocer las características de la región patagónica para no definirla como un "desierto", sino como una zona semiárida, proveedora de forrajes a millones de animales, pero que con un "uso debido" de sus escasos recursos llegaría a ser más productivo. También abogaba por la reglamentación del uso para frenar el manejo y la ocupación "desordenados" ${ }^{27}$ y retomar el movimiento de los rebaños en distintos terrenos según las estaciones para el pastoreo. ${ }^{28}$ Otro ejemplo se encuentra en un informe de la Comisión Exploradora de Parques Nacionales donde se afirmaba que había una ausencia de preocupación por parte de los ocupantes de las tierras por la conservación de sus campos y por las consecuencias de ese descuido en el largo plazo. ${ }^{29}$

Así mientras la "hostilidad" de los territorios patagónicos se consideraba que estaba siendo superada por la acción del hombre patagónico y la ganadería, también se comenzaba a reconocer en las dificultades del suelo, las condiciones climáticas y la acción del pisoteo los causantes del deterioro, de la "erosión" y de la pérdida de la productividad de la tierra. Asimismo, se sustentaban estos razonamientos en la existencia de estudios y opiniones de científicos "reconocidos", ${ }^{30}$ dando los primeros signos de una valorización del conocimiento científico por sobre el tradicional o local.

En esta misma línea, la Sociedad Rural Argentina reconocía en su memorial de 1936 la desaparición de especies forrajeras - con la consecuente reducción de la capacidad ganadera -, un desinterés en la conservación por la inseguridad en la titularidad, y el avance acelerado del ovino hacia nuevas tierras debido al auge de los precios en la primera posguerra. Así se fue desarrollando una ocupación del territorio basada en una forma de producción que no tenía en cuenta las capacidades de la tierra para desarrollarse. ${ }^{31}$

Algunos años más tarde, la crítica a las formas de uso de la naturaleza se extendería, pero enfocada y con una valoración negativa respecto a los chilenos.- En la revista Argentina Austral, se denunciaban los atropellos de los "indeseables" por sus prácticas de explotación de los recursos naturales, "atentaban contra las bellezas naturales cordilleranas" y Amaya, un productor local, sostenía sobre los indígenas:

\footnotetext{
${ }^{24}$ Rodríguez Romero, "Ganadería y erosión en Patagonia".

${ }^{25}$ Brígida Baeza y Daniel Borquez, "La Ganadería ovina en el Chubut", Observatorio de la Economía de la Patagonia, 2006, http://www.eumed.net/oe-pat. Fernando Coronato," "El rol de la ganadería ovina en la construcción del territorio de la Patagonia" (Tesis de Doctorado en Geografía, AgroParisTech (Institut des Sciences et Industries du Vivant et de l'Environnement), 2010).

${ }^{26}$ Ramón Gorraiz Beloqui, "Excesos en el pastoreo", Argentina Austral XXXII, n. ${ }^{\circ} 352$ (1961): 41-43.

${ }^{27}$ Roberto Risso Patrón, "Estudio sobre producción, comercialización e industria de la lana en Santa Cruz y Tierra del Fuego" (Buenos Aires: Consejo Federal de Inversiones, 1973): 19.

28 Larry Andrade, "Producción y ambiente en la Meseta Central de Santa Cruz, Patagonia austral en Argentina: desencadenantes e impacto de la desertificación", Ambiente y Desarrollo XVI, n. ${ }^{\circ} 30$ (2012): 73-92.

${ }^{29}$ Regina Schülter, Chubut: turismo, hábitat y cultura (Buenos Aires: Facultad de Ciencias Económicas, UNPSJB, 1996).

${ }^{30}$ Leónides Aleman, "Problemas del agro patagónico", Argentina Austral IX, n. ${ }^{\circ} 108$ (1938): 31-33.

${ }^{31}$ Larry Andrade, Otoño en la estepa (Buenos Aires: La Colmena, 2010).
} 
Sobre los valles del Nahuel Pan [...] a medida que los "intrusos" destruyen la capacidad zootécnica de esos campos y aniquilan el bosque, sin otro ulterior destino que el de alimentar fogones donde se asan las haciendas robadas" y sobre los chilenos "sobre la frontera con Chile [...] la población nómade que merodea por esos parajes y practica la antigua costumbre de abrir claros en la floresta, por medio del fuego. ${ }^{32}$

Las ideas de "hostilidad" y "desierto" fueron dominantes para caracterizar el paisaje en estos inicios de la ocupación "blanca". La acción del hombre buscaba superar los avatares y las "duras" condiciones que tenía este territorio para poder ocuparlo e incorporarlo al "desarrollo" nacional. La ganadería ovina sería considerada la única actividad viable, la cual, además, podía llevarse a cabo con baja inversión de capital y trabajo. Sin embargo, el crecimiento exponencial de la actividad hizo que ya en las primeras décadas del siglo XX, la "erosión" que la naturaleza y la propia ganadería generaban, introdujera la interpretación sobre la misma como "indómita".

\section{Naturaleza indómita}

A mediados del siglo $X X$, se volvieron recurrentes y con trascendencia pública las interpretaciones sobre dificultades generadas por las características "naturales" de la región, aunque ya en esa época era una naturaleza antropizada, modificada por el hombre. La referencia con mayor presencia remitía al deterioro de las capacidades productivas que permitía esa naturaleza. En la década de 1960 algunos pobladores se quejaban porque "los campos se han venido a menos" y "que la capacidad ganadera ha disminuido considerablemente", al punto de hablar de una "devastación de los campos". ${ }^{3}$ La naturaleza era el principal causante de dicho deterioro por la escasez de lluvias, la acción de los vientos y en menor medida, las nevadas. A modo de ejemplo:

Las grandes nevazones invernales, las lluvias y sobre todo la ventisca o el huracán, coartan toda actividad social o económica, a la par que disipan toda posibilidad de intercomunicación dentro y fuera de la región. ¿Qué puede hacer el hombre frente a la presión de un ambiente natural indómito y hasta cierto punto deprimente? ? $^{34}$

Pese a este deterioro, el "monocultivo" ovino continuaba siendo justificado porque eran "los únicos animales capaces de producir económicamente" en esa zona, según las palabras de un importante economista agrario argentino en la época, Horacio Giberti. ${ }^{35}$ Sin embargo, algunos comenzaban a interpretar que esa "inevitable" respuesta o adaptación a las características del paisaje podía generar un mayor deterioro del mismo si no se

\footnotetext{
32 Baeza, Fronteras e identidades en Patagonia Central (1885-2007), 87.

${ }^{33}$ Abel Moray, "Acerca del problema de los campos devastados", Argentina Austral XXX, n. ${ }^{\circ} 346$ (1960): 9.

${ }^{34}$ Antonio Vivanco, "Influencias en la vida rural patagónica", Argentina Austral XXI, n. ${ }^{\circ} 333$ (1959): 34-35., 34.

${ }^{35}$ Risso Patrón, "Estudio sobre producción, comercialización e industria de la lana en Santa Cruz y Tierra del Fuego".
} 
controlaba la carga de hacienda de los campos. ${ }^{36}$ Así algunas prácticas sobre la naturaleza como el pastoreo excesivo o sin control, la falta de preocupación por los recursos, ${ }^{37}$ los incendios de campos y extracción de arbustos y la ausencia de suficientes alambrados que generaban un deambular "errático" de las ovejas podían generar el deterioro.

La cuestión del alambrado se ligaba a otro factor mencionado como determinante en el deterioro: la "inseguridad" en la propiedad de la tierra. Ésta llevaba a una explotación intensa para poder obtener rápidos resultados ${ }^{38}$ y si se entrega la propiedad iba a ser un aliciente para "la conservación y el mejoramiento de las especies forrajeras" y al "cuidado de la productividad del suelo y la defensa contra los factores climáticos adversos" que iban a asegurar "la prosperidad futura de los abnegados pobladores del Sur, quienes por fin tendrán acceso a la propiedad de la tierra que trabajan y aman". ${ }^{39}$

Frente a estas interpretaciones de la naturaleza las soluciones se enmarcaban en la idea de un "manejo racional". Aparecía la relación directa entre la racionalidad como forma de manejo y la preservación de los suelos. Esta racionalidad estaba ligada, implícita o explícita a la aplicación de métodos y formas de manejo basadas en el conocimiento científico, como cuando en Argentina Austral se hablaba de "explotación anticientífica del suelo". ${ }^{40}$ La propuesta de un manejo racional estaba en clara relación con una construcción científica sobre el "deterioro" de la naturaleza, motivada por la presencia de estudios en la región por parte de organismos de ciencia y técnica: Gorraiz Beloqui en la revista Argentina Austral, retomaba palabras del Ingeniero Agrónomo Alberto Soriano quien, en su visita a la región en el año 1953 como miembro del Instituto Botánico del Ministerio de Agricultura y Ganadería, recomendaba la revisión seria de la carga animal y la implementación de un manejo "más racional" porque si no se iniciaría un camino hacia la desertización. ${ }^{41}$ Pero principalmente se evidencia la influencia científica- tecnológica por la instalación en la provincia de dependencias del Instituto Nacional de Tecnología Agropecuaria (INTA) en la década de $1960 .^{42}$

El manejo racional implicaba el reemplazo de vegetación nativa, incluyendo la "destrucción" de plantas consideradas indeseables por su escaso valor forrajero, por siembra de especies forrajes más "nutritivas" para el ganadero. También se incluían prácticas de manejo, como la rotación de potreros y la división de aquellos que eran muy extensos y la generación de aguadas. ${ }^{43}$ En esta línea, para algunos, la solución no radicaba en la eliminación del pastoreo (lo que hoy en día se conoce como clausura) sino en la "adaptación" permanente a la capacidad de sustentación de la vegetación, es decir, lo que actualmente se conoce como la disminución del nivel de carga animal. Por último, también existía la posibilidad de realizar obras hidráulicas, como diques o canales. Aunque la erosión o el deterioro comenzaba a preocupar a los pobladores, algunos no veían posible afrontar los efectos de la naturaleza y reclamaban por la acción del Estado, principalmente a través

\footnotetext{
${ }^{36}$ Vivanco, "Influencias en la vida rural patagónica".

${ }^{37}$ Véase: Diario Esquel, 24 de junio de 1961:4

${ }^{38}$ Alberto De Vita, "Capacidad aparente y capacidad real de los campos de pastoreo", Argentina Austral XXII, n. ${ }^{\circ} 234$ (1951): 13-18.

${ }^{39}$ Ricardo Fisch, "Liberación de la tierra fiscal", Argentina Austral Selección de artículos Tomo I, n. ${ }^{\circ} 301$ (1956): $514-16$.

40 Véase: "Problemas del campo austral y soluciones propuestas", Argentina Austral Selección de artículos Tomo I, n. 358 (1961): 555-58.

${ }^{41}$ Gorraiz Beloqui, "Excesos en el pastoreo".

${ }^{42}$ Núñez y López llevan este argumento al extremo, al punto de sostener que fue el INTA quien impulsó la ovinización de la Patagonia, en Paula Gabriela Núñez y Silvana López, "Lo rural y lo científico: La instalación de la Estación Experimental Regional Agropecuaria (EERA) INTA Bariloche 1962-1968", Estudios Rurales 4, n. ${ }^{\circ} 7$ (2015), http://ppct.caicyt.gov.ar/index.php/estudios-rurales/article/view/5496

${ }^{43}$ Véase "Erosión: nuevo mal que azota a la Pātagonia", Argentina Austral XXVIII, n. 300 (1956): 18-21. "Necesidad y posibilidades de combatir la erosión", Argentina Austral XXXV, n. ${ }^{\circ} 385$ (1963): 15. Gorraiz Beloqui, "Excesos en el pastoreo".
} 
de la derogación de impuestos y retenciones, o de las asociaciones de productores. ${ }^{44}$ Otro especialista en ganadería, Antonio López Arias sostenía: "Al amparo de la propiedad de la tierra, toca hoy a los ganaderos patagónicos enfrentar la realidad de sus campos menguados en posibilidades, adoptando sistemas de explotación en armonía con las exigencias de cada medio". ${ }^{45}$

Esta interpretación fue tan predominante que se tradujo en la agenda pública y se institucionalizó en normativas del Estado. Por ejemplo, la Constitución provincial de 1957 incluyó algunos principios para el desarrollo de una ganadería preservadora del recurso, determinando la importancia del cuidado del suelo, por su carácter natural, pero, principalmente, por ser un recurso productivo. En la misma línea estuvo un proyecto de ley de suelos en 1961 que buscaba tanto la defensa de riquezas naturales como la "racional explotación de la tierra" ${ }^{46}$ Este enfoque es coincidente con una etapa histórica conocida por los estudiosos de las cuestiones ambientales como naturaleza modernizada, en la que el cuidado de la tierra buscaba incrementar su utilidad y favorecer al desarrollo de las actividades productivas, como en el caso de estudio era la ganadería. ${ }^{47}$

Pese al predominio de la racionalidad cientificista, como en el pasado coexistía con explicaciones y propuestas de acciones del hombre respecto a la naturaleza basadas en ideas místicas o religiosas sobre las manifestaciones de la naturaleza, consideradas como medio de expresión de una divinidad: ${ }^{48}$

Si bien varios pobladores han individualizado las razones de dicho proceso tan lamentable y han orientado sus esfuerzos hacia un mayor número y una más adecuada distribución de las fuentes de agua, acompañada por una mayor división mediante aumento de alambrados, no deben olvidarse que, aparte de los que por razones obvias no se preocupan de otra cosa que de la esquila, son innumerables los casos en que se explota la creencia de que los campos se vinieron abajo porque ahora no llueve, ni nieva como antes. Y a ese respecto no tienen eficacia alguna tanto las estadísticas pluviométricas, que demuestran la absoluta inconsistencia del argumento, como tampoco el hecho de quie, donde no hay más raíces y donde las pocas semillas que se producen carecen de todo reparo que las proteja del viento, el agua de lluvia por más abundante que sea no puede hacer milagros. ${ }^{49}$

Cuando el agua abunda la Patagonia produce y la acción perseverante del hombre no cae en el vacío. Ese es su incentivo. Y esto constituye el justo premio de la madre tierra, que agradecida devuelve a sus hijos en forma de bendición los frutos de su trabajo, producto de su tesón. ${ }^{50}$

\footnotetext{
${ }^{44}$ Véase: Claude Ducloux, "Perspectivas favorables del mercado lanero", Argentina Austral XXXI, n. ${ }^{\circ} 336$ (1959): 31. "Viento, sequía y otros males del campo patagónico", Argentina Austral XXXII, n. ${ }^{\circ} 356$ (1961): 35-36.

${ }^{45}$ Antonio López Arias, "El mejoramiento ovino y las condiciones del medio", Argentina Austral Selección de artículos Tomo I (1958): 476.

46 "Ley de suelos en Chubut", Argentina Austral XXXIII, n. ${ }^{\circ} 361$ (1961): 56.

${ }^{47}$ Este enfoque es coincidente con una etapa histórica conocida por los estudiosos de las cuestiones ambientales como naturaleza modernizada en la que el cuidado de la tierra buscaba incrementar su utilidad y favorecer al desarrollo de la ganadería. Palacio, "Breve guía de introducción a la Ecología Política (Ecopol): orígenes, inspiradores, aportes y temas de actualidad".

${ }^{48}$ Este tipo de explicaciones no era novedoso en el continente americano, donde ha estado presente para explicar los desastres naturales desde la época de la colonia y por ello no pueden entenderse los problemas ligados a la naturaleza si no se considera esta convivencia de interpretaciones. Mires, El discurso de la naturaleza: ecología y política en América Latina. Margarita Gascón, Percepción del desastre natural (Buenos Aires: Biblos, 2009).

${ }^{49}$ De Vita, "Capacidad aparente y capacidad real de los campos de pastoreo", 15.

${ }^{50}$ Dagoberto Viola, "El problema patagónico del agua", Argentina Austral XXXII, n. ${ }^{\circ} 34$ (1961): 32-33, 33.
} 
A medida que el deterioro fue avanzando en algunas zonas, empezaron a encontrarse interpretaciones sobre los cambios en la disponibilidad de forraje donde se combinaban distintos problemas ambientales: las sequías con la ausencia de nevadas generaban el avance de la formación de "voladeros", lugares sin presencia de vegetación, los cuales se agrandaban con los fuertes vientos estivales. Frente a ellos, y ligado a algo que será central en las décadas siguientes, se juzgaban las distintas prácticas según el tipo de productores: mientras que los grandes establecimientos habían podido identificar estos voladeros a tiempo, cercarlos y sembrarlos, los medianos no lo hicieron porque la tierra era fiscal y no consideraban productivo invertir los beneficios en cuidar la tierra que no era propia. $^{51}$

De este modo, frente a la naturaleza "indómita", el principal objetivo de los agentes sociales respecto a la naturaleza era lograr "dominarla". El deterioro de las capacidades productivas de las tierras secas chubutenses era la principal dificultad. A los causantes naturales se le sumaron otro tipo de explicaciones como las basadas en creencias o prácticas religiosas, pero sobre todo las que asignaban el deterioro a la acción del hombre (quien había contribuido al deterioro y también debía actuar si quería mantener la expansión de la ganadería ovina). La solución propuesta era el manejo "racional" dando cuenta del avance del conocimiento científico- técnico para la explicación de la cuestión ambiental en la zona y su consecuente desvalorización de otros saberes, explicaciones y prácticas. Sin embargo, el método de manejo predominante en la ganadería ovina continuaría siendo de carácter extensivo, mientras se seguía incrementando la cantidad de cabezas de ganado para sostener la rentabilidad de la actividad. ${ }^{52}$

\section{Naturaleza armoniosa}

Hacia finales del siglo XX, la naturaleza de las tierras secas era interpretada de forma dominante en su relación con la degradación y la pérdida de productividad para la ganadería ovina. Pero a diferencia de los momentos anteriores, estas interpretaciones se basaban en causas antrópicas, evidenciando el carácter ambiental y no natural de dichos problemas. ${ }^{53}$ Principalmente se mencionaban el exceso de cantidad de ganado (sobrecarga animal) y el "monocultivo" o monoproducción ovina. Por ejemplo, investigadores de la Facultad de Agronomía de la Universidad de Buenos Aires en 1990 afirmaban que, en función de los estudios realizados en Chubut, se podía evidenciar que los encargados de determinar la forma del pastoreo de los campos tenían una visión de las pasturas "grosera" y "borrosa". Realizaban un manejo no cuidadoso, por el carácter "natural" y "sin costo" del pasto y porque basaban sus decisiones según sus necesidades y no en función de la oferta y demanda de forraje. Así los agrónomos culpabilizaban a los productores o los administradores de los campos, quienes no se guiaban por la complejidad de la situación ambiental para tomar sus decisiones. Consideraban necesaria la implementación de cambios en el manejo (pese a que no podían asegurar la efectividad de los resultados, dada la combinación de variables presentes en cada momento y espacio) y la educación para modificar actitudes en el ámbito de la política y de la producción. ${ }^{54}$

\footnotetext{
${ }^{51}$ Se sostenía que la tierra "se podía perder en cualquier momento frente a alguien con mejores "padrinos'" "Los voladeros del Chubut", Argentina Austral, 1962, XXXIII (368), 18-19.

${ }^{52}$ Larry Andrade, Sociología de la desertificación: los productores ovino extensivos de la patagonia austral (Buenos Aires: Miño y Dávila, 2005).

${ }^{53}$ Este proceso es coincidente con el desarrollo de la ecología y de los estudios ambientales.

${ }^{54}$ Alberto Soriano y José Paruelo, "El pastoreo ovino: principios ecológicos para el manejo de los campos", Ciencia Hoy, mayo de 1990
} 
Asimismo, se volvieron evidentes otras valoraciones diferenciales respecto a las prácticas de uso de los suelos y las condiciones de la vegetación según las realizaran pequeños o grandes productores. En general culpabilizaban a los primeros por el deterioro generado por el sobrepastoreo. A modo de ejemplo, Sourrouille analiza la obra de Julián Ripa (maestro y abogado en la región), mostrando el contraste entre la situación de las tierras en la Colonia Cushamen y la Compañía de Tierras del Sud: "El alambrado divide dos zonas nítidamente distintas. De un lado, la Colonia, de parda tierra devastada por el sobrepastoreo. Del otro, el verde tupido de un campo reservado". ${ }^{55}$ Esta comparación también se realizaba respecto a otros campos de la zona, donde había una relación directa entre la cantidad de ganado y de población que vive de esas tierras y el nivel de degradación por sobrepastoreo. En esta línea, otras interpretaciones consideraban que el minifundio no contribuía a la lucha contra la erosión: según un informe del INTA Bariloche en 1990, aunque era discutible si el minifundio era la principal causa de la erosión, era incontrovertible el hecho de que ese tipo de productores estaban "incapacitados de realizar las inversiones necesarias para la recuperación del suelo. Por otra parte tampoco podrán mantener, en el largo plazo, la mayor parte de las inversiones que realizare el Estado para combatir la degradación del recurso" . 56 Para Baetti, Cornaglia y Salvia, la desertificación y el minifundio generaban un círculo vicioso de deterioro creciente. ${ }^{57}$ Así la degradación de la tierra comenzaba a ser interpretada como consecuencia de un determinado uso, acceso y distribución del "recurso tierra".

Las interpretaciones sobre la incidencia de la acción de la fauna silvestre en la desertificación de la tierra también presentaban divergencias. Mientras algunos culpabilizaban al guanaco, especie autóctona, por su consumo forrajero, al punto de considerarlo una plaga; ${ }^{58}$ otros investigadores afirmaban que este animal tiene un menor impacto sobre los pastizales que el ganado ovino y que el tamaño de su población siempre estuvo en relación a las posibilidades de sustento que le brindaba la naturaleza. ${ }^{59}$

Pese a las divergencias, en 1994 ocurrió un hecho importante que determinó lo que Marteen Hajer denominaría "clausura discursiva" . 60 la definición y adhesión de Argentina a la Convención Internacional de Lucha contra la Desertificación, ${ }^{61}$ la cual llevaba a que se entendiera al problema del deterioro como "desertificación" y se promoviera la "clausura del problema" a través del acceso a proyectos financiados por organismos internacionales, en el marco de los discursos sobre la sustentabilidad como clave para el desarrollo. ${ }^{62}$ Sin

\footnotetext{
${ }^{55}$ Sourrouille, "Estrategias agropecuarias, sustentabilidad y políticas públicas: una propuesta de historia ambiental para el noroeste del Chubut (1890-2010)", 13.

${ }^{56}$ Ernesto Barrera, "Política agropecuaria patagónica: el minifundio ovino", Comunicación técnica n 10 (San Carlos de Bariloche: Instituto Nacional de Tecnología Agropecuaria, 1990), 2-3.

${ }^{57}$ Carlos Baetti, Ana Cornaglia, y Agustín Salvia, "Balance y perspectivas de los cambios ocurridos en el mercado de trabajo rural en el extremo sur de la Argentina", en La Patagonia de los noventa. Sectores que ganan, sociedades que pierden, ed. Agustín Salvia (Buenos Aires: La Colmena, 1999).

${ }^{58}$ Roberto Masera, La meseta patagónica del Somuncura: un horizonte en movimiento (Viedma: Gobiernos de las Provincias del Chubut y Río Negro, 1998).

59 Alí Mustafá, "En la Patagonia avanza el desierto", Servicio informativo iberoamericano, septiembre de 1999 , http://www.oei.org.co/sii/entrega21/art03.htm.

${ }^{60}$ Marteen Hajer, The politics of environmental discoiurse (Oxford: Clarendon Press, 1995).

${ }^{61}$ Véase: Programa de Acción Nacional de Lucha contra la Desertificación, "Documento Base" (Buenos Aires: Ministerio de Ambiente, 1997), http://www.ambiente.gov.ar/?idseccion=143. Hugo Méndez Casariego, Patagonia: el INTA lucha contra la desertificación, INTA Informa, 2010, http://intainforma.inta.gov.ar/?p=438.

62 Los planteos del desarrollo sustentable se relacionaban con el paradigma económico de la "administración de recursos", el cual proponía la inclusión de todos los tipos de capital y de recursos en el cálculo de las Cuentas Nacionales, la productividad, el diseño de políticas de desarrollo y planes de inversión. Para ello, impulsaba como estrategias de manejo y tecnologías, las evaluaciones de impacto y de manejo de riesgo, el consumo eficiente, la conservación de recursos renovables y su renovación; la investigación a través de modelos y planificaciones biofísicas y económicas; y las políticas como impuestos e inclusive el principio del "contaminador paga". Véase: Nicolás Gligo, Estilos de desarrollo y medio ambiente en la América Latina (México, D.F.: Fondo de Cultura Económica, 2006). Julio Penna y Estela Cristeche, La
} 
embargo, aunque desde esta nueva perspectiva se promovía políticas que buscaban desarrollar y "acelerar la adopción de la tecnología disponible para el uso sustentable de los recursos naturales", 63 se seguía sosteniendo la necesidad de un uso y manejo "racional" del pastoreo.

Este período se destacó por el cambio de punto de foco de los problemas ambientales hacia los suelos, considerados tanto como el objeto del problema, como el de las soluciones y la definición del deterioro de las tierras secas pasó de ser la erosión a la desertificación. Este cambio no era simplemente de nominación: implicaba el reconocimiento de que el deterioro tenía causas que no eran naturales, aunque no todos los grupos sociales parecían haber contribuido a él en el mismo sentido. Resultaba indudable que la acción del hombre era necesaria para trabajar en la resolución de estos problemas y para ello se debía lograr una "armonía" con la naturaleza y sus procesos. En este marco lejos de abandonar la idea del manejo racional, se incluía la sustentabilidad como objetivo en las propuestas de manejo y las políticas públicas en torno a la problemática ambiental.

\section{Una diversidad de interpretaciones sobre la naturaleza en la actualidad}

En la actualidad, existe una heterogeneidad de interpretaciones sobre la naturaleza en las tierras secas chubutenses que muestran las huellas del pasado y los cambios tanto en los sentidos otorgados como en las prácticas realizadas. Están quienes presentan a la naturaleza como "externa" a las acciones del hombre y de las sociedades. Para ellos, la naturaleza puede ir cambiando, como a través de la reducción de las lluvias y las nevadas en los inviernos o el clima volverse menos hostil, pero estas modificaciones no tienen impactos en cuanto a sus posibilidades productivas, la realización de sus prácticas de trabajo o inclusive su calidad de vida. Inclusive, el origen de los cambios es considerado que radica en la misma naturaleza y ella también se encargaría de las soluciones: "Con un año que venga nevador, ya vuelve [el pasto]" (Entrevista a A., productor, Paso del Sapo, 2011).

En estos casos, tampoco se reconoce que la producción o el trabajo con la ganadería ovina han generado algún impacto o cambio en la naturaleza.

Entrevistadora: ¿creen que va a cambiar o que esta sequía es algo que va a quedar así?

Entrevistado: Esperamos que la lluvia, la lluvia. Acá no tiene la culpa el gobierno, ni nadie.

Entrevistada: No lo va a arreglar nadie. Es parte de la naturaleza (Entrevista a productores, Gan Gan, 2014)

Sin embargo, ésta no es la interpretación dominante. En nuestros días, la mayoría de los agentes sociales en la zona de análisis incluye a la naturaleza dentro de sus propias "realidades", aunque con diferentes matices en cuanto a su valoración y a las acciones que

valoración de los servicios ambientales: distintos paradigmas, Estudios socioeconómicos de la sustentabilidad de los sistemas de producción y recursos naturales 2 (INTA, 2008). El supuesto consenso social y académico que hizo que predominara en la agenda pública mundial y se utilizara en múltiples sentidos. Eduardo Sevilla Guzmán y A. Alonso Mielgo, "Sobre el discurso ecotecnocrático de la sostenibilidad", en Agricultura y desarrollo sostenible, ed. A. Cárdenas (Madrid: MAPA, 1995).

${ }^{63}$ INTA y GTZ, "Proyecto Integrado: Prevención y control de la desertificación para el desarrollo sustentable de la Patagonia", 6. 
deberían desarrollar respecto a ellas para poder enfrentar el deterioro. Como en el pasado, algunos continúan considerándola como un "enemigo" a ser combatido o, por lo menos, controlado. Otros agentes sociales buscan el desarrollo de una relación "armónica" con la naturaleza. Para algunos esta "armonía" se logra a través de la conexión con las tradiciones, con dioses o con una forma de vida que incluyen al hombre como parte de esa naturaleza y que por el abandono de esos vínculos o ritos, ha sido castigado con el deterioro natural.

La gente antes estaba más relacionada con la naturaleza y los climas eran otros. Hoy la gente ya somos, estamos pisando sobre la tierra, pero a veces no hacemos nuestras ceremonias, no se hacen ceremonias. $Y$ el clima empieza a cambiar, la misma gente que antes estaba en contacto con la naturaleza y hoy mismo nosotros estamos, pero no tenemos ese conocimiento que ellos tenían. Entonces pasa esto [que no llueve] (Entrevista a P., productor, Vuelta del Río, 2014)

Yo me acuerdo cuando tenía 7 años, 8 hacían Camaruco ${ }^{64}$ y entonces se contestaba, pero hoy en día no, ¿sabes por qué? porque no hay, no hay unión entre la gente, entre nosotros mismos nos estamos peleando, ¿viste?, claro, y ese es el problema. El Camaruco era una cosa respetable de antes, después se fue perdiendo, porque la gente no respetó. (Entrevista a L. productor, Las Salinas, 2014)

Y para vender más, hay que producir más. Para producir más hay que darle más comida. Y para eso tiene que ayudarnos de arriba, con un poco más de Iluvia. (Entrevista a R., productor, Esquel, 2011)

Por último se encuentran quienes promueven la "adaptación" a las (nuevas) características que surgieron a lo largo de los años y critican a los productores, al Estado o a ambos, por la falta de acciones para enfrentar el deterioro.

Va a existir, existió, va a existir, existe y va a existir, digamos, la sequía va a seguir existiendo, va a seguir causando este problema, pero nosotros no hacemos nada para adaptarnos a esta situación. Entonces lo único que hacemos es poner plata cuando viene la sequía. Llueve y nos olvidamos. Nos olvidamos. ¿Viste? Y la cosa y si sube el precio de la lana, listo, se terminó el problema. Nadie más se acordó y la degradación sigue existiendo. (Entrevista a T., técnico, Esquel, 2011)

Porque la naturaleza está diciendo que baje [la carga animal] (...). El hombre metido en el medio, que siempre que el hombre se mete en algo... influye y molesta al medio ambiente. Pero... creo que en este momento, la naturaleza

\footnotetext{
${ }^{64}$ El Camaruco es una ceremonia tradicional de los pueblos originarios, con la que se busca, entre otros motivos, pedir por agua y lluvias para el siguiente año. Muchos de los integrantes de estos pueblos consideran que sólo pueden realizarlo quienes tienen "el don" para hacerlo, el cual se hereda de la familia o se anuncia en los sueños a los ancianos de la comunidad. Otra práctica similar son las rogativas de agua. El abandono de estas ceremonias durante muchas décadas (por el castigo a quienes hablaban la lengua o practicaban la religión, especialmente en las escuelas), la migración y el avance de formas culturales "occidentales" o "modernas" motivan a que algunos grupos consideren que el deterioro de la tierra es consecuencia de un cambio en el vínculo con la naturaleza y que no vean que se puede modificar porque creen que no hay quienes sepan realizar las ceremonias con el respeto que requieren.
} 
está poniendo en orden algún número de cosas para que nos dejemos de joder y trabajemos como debemos trabajar. (Entrevista a M., técnico y productor, Esquel, 2011)

Esta heterogeneidad de interpretaciones de la naturaleza claramente no puede motivar prácticas homogéneas dentro de la región y, especialmente, en la ganadería ovina que continúa siendo la principal actividad económica. En este sentido, especialmente ligada a la asignación de causas y soluciones en la naturaleza, se sostiene el modelo extensivo clásico de producción de la lana, en el cual algunos ganaderos continúan llevando adelante prácticas que no han variado desde los inicios de la actividad a fines del siglo XIX. En contraposición, y relacionado al reconocimiento de la necesidad de "adaptación" o de una relación más "armónica" con la naturaleza, ciertos productores han introducido distintas prácticas, entre las cuales algunas conllevan importantes inversiones de capital, tecnología y trabajo y como su adopción no es generalizada, por ahora, no se puede hablar de un cambio en el modelo de producción ganadero. Como ejemplos, se pueden mencionar el manejo holístico, la suplementación alimentaria estratégica, manejo e intersiembra de mallines, procesos de certificación de calidad (inclusive de tipo ambiental) y estrategias complementarias a la producción de lanas como el desarrollo de carne ovina a través de la cría de nuevos biotipos de ovinos, la elaboración de hilados y tejidos artesanales. ${ }^{65} \mathrm{La}$ incorporación de muchas de estas prácticas está restringida para los pequeños productores poco capitalizados, pero, desde la perspectiva de los agentes sociales, esto no lleva necesariamente a que este estrato de productores sea el culpable del deterioro ambiental. Un argumento así difícilmente podría sostenerse ya que se evidencia que algunos grandes productores también mantienen modos de producción extensivos y baja incorporación de las prácticas que no generan deterioro, con lo cual no contribuyen a frenar y/o revertir el proceso de desertificación.

Así, y aunque la naturaleza es considerada de forma diferente por los agentes sociales, la interpretación dominante continúa sosteniendo los argumentos descriptos respecto a un lenguaje de valoración productivista, centrado en su importancia económica para permitir desarrollar la ganadería ovina y la obtención de lanas. Su deterioro o sus problemas sólo se piensan en función de una causa- efecto para la continuidad o el freno de esta actividad económica: "El ambiente, para lo único que da, es para las [pausa] ràzas de pelo" (Entrevista a J., técnico, Esquel, 2011).

Sin embargo, este lenguaje de valoración que pone el foco en la ganadería ovina y su productividad comienza a ser disputado. En los últimos años, ha comenzado un debate, una disputa que puede modificar este predominio y plantear nuevas interpretaciones respecto a la naturaleza de las tierras secas chubutenses. Tal como ha sido detectado por Andrade ${ }^{66}$ en Santa Cruz, y Conti y Núñez ${ }^{67}$ en Río Negro, las zonas áridas de la Patagonia podrían proveer de otros "recursos naturales" hoy sumamente demandados en el mundo: los minerales. Ligados a emprendimientos de gran envergadura, con capitales extranjeros, no sólo introducen, para algunos, una posible alternativa frente al deterioro de la naturaleza por parte de la ganadería ovina, sino también cuestionamientos sobre el destino de recursos

\footnotetext{
${ }^{65}$ Veáse: Autor, 2013.

${ }^{66}$ Andrade, "Producción y ambiente en la Meseta Central de Santa Cruz, Patagonia austral en Argentina: desencadenantes e impacto de la desertificación".

${ }^{67}$ Conti y Núñez, "La violençia del silencio, las mujeres de la estepa".
} 
muy valiosos para la región, como el agua, que ha sido encontrada en diversos casos como parte de los procesos de exploración de las compañías mineras. ${ }^{68}$

\section{Epílogo}

Pese a que la teoría social se concentró, durante muchas décadas, en intentar explicar los fenómenos y procesos sociales planteándolos como "ajenos" o sin considerar a la naturaleza, en la actualidad este tipo de explicaciones no permiten dar cuenta de la realidad social. Sin negar la base material presente en los problemas ambientales, las formas de interpretación, el lenguaje de valoración y los sentidos otorgados resultan centrales para explicar los usos y problemas de la naturaleza.

La situación actual se caracteriza por la heterogeneidad de interpretaciones sobre la naturaleza en esta región, especialmente sobre el problema de desertificación de las tierras. Como consecuencia, las prácticas sociales también son heterogéneas y no siempre contribuyen a frenar o reducir los impactos de la acción de la sociedad en la naturaleza. Especialmente en el plano de las prácticas en torno a la naturaleza, es importante resaltar que, como se muestra en esta historia, tampoco son neutras a una valorización social sino que han sido ponderadas positiva o negativamente según los grupos sociales que las han desarrollado. Principalmente, pueblos originarios, chilenos, ocupantes sin títulos de propiedad y pequeños productores han sido sucesivamente culpabilizados por el deterioro.

Si bien estas fueron interpretaciones dominantes, es claro que siempre están presentes otras formas de considerar a la naturaleza. En particular en esta región coexisten explicaciones sobre los cambios en la naturaleza donde se incluyen razonamientos científicos, tecnológicos, religiosos y culturales. Como sostiene Margarita Gascón no se pueden explicar las prácticas en torno a la naturaleza sólo desde el plano científico sino que es importante considerar, especialmente en los momentos de diseño de políticas públicas, que hay otras prácticas y otros sentidos puestos en juego.$^{69}$

La coexistencia de interpretaciones sobre la naturaleza inclusive sucede en esta región y con agentes sociales vinculados a una producción económica que desde sus inicios se basó en una forma de producción capitalista, mercantilizadora de la naturaleza, pero subvalorada respecto a las potencialidades económicas de las áreas colindantes. Por ello probablemente se reconoce en este recorrido de interpretaciones, el predominio de un lenguaje de valoración productivista, el cual no es reciente. Por lo menos desde las exploraciones científicas de fines del siglo XIX, la valoración de la naturaleza árida se hizo en función de su única capacidad para desarrollar la ganadería ovina y las primeras investigaciones científicas también tuvieron como fin el mejorar o, por lo menos, sostener dicha actividad productiva. En este sentido, interpretaciones que apunten a la conservación de los ecosistemas de las tierras secas sin la intervención del hombre o a un discurso de valoración de estos espacios por su carácter natural fueron muy poco mencionados y no lograron imponerse en la agenda pública y determinar otros modos de accionar del Estado u otras prácticas en esta zona.

De esta manera, en el caso chubutense, ${ }^{70}$ detrás de las interpretaciones predominantes sobre la naturaleza pareciera esbozarse la necesidad de "ocuparse",

\footnotetext{
${ }^{68}$ En Chubut, el más importante fue el acuífero encontrado en la zona de Gan Gan, en el noreste provincial en el año 2011 (Diario Jornada, 27/7/11).

${ }^{69}$ Gascón, Percepción del desastre natural.

${ }^{70}$ Este tipo de diferenciales también han sido relēvados en otras zonas áridas, por ejemplo, veáse: Benjamín Constantini y Andrés Pedreño Cánovas, "Aridez y construcción social del riesgo en las tierras del sureste español: una-aproximación a la
} 
"cuidar" y "arreglar" las tierras secas, como si desde ese espacio y sus habitantes no pudieran hacerlo por sí mismos. Podría considerarse que existe una actitud paternalista respecto a la naturaleza de esta zona, especialmente cuando proviene desde el Estado y los organismos técnicos. Estas demarcaciones, límites hechos a través de los sentidos no son ingenuos, sino que tienen claros impactos en las prácticas sociales y en las políticas públicas. Por un lado, posibilitan usos abusivos y distribuciones concentradas e inequitativas de la naturaleza, y generan propuestas de soluciones o de modos de enfrentar sus cambios que no siempre contemplan las interpretaciones, intereses y prácticas de las poblaciones locales. Por otro, porque cuando la naturaleza se vuelve un problema o porque tiene ciertas características de las cuales "ocuparse", se determinan sitios "afectados" y "no afectados", beneficiarios y excluidos de dichas políticas según el lugar donde produzcan o habiten. También se definen "culpables" de los cambios y de la degradación de los recursos. Estas determinaciones que no son incuestionables, sino que son objeto de debate y no siempre contribuyen a trabajar con la naturaleza de un modo que no agrave su deterioro.

sociología del desierto", en Globalización, desarrollo y territorios menos favorecidos, de Alberto Riella (Montevideo: Departamento de Sociología, Facultad de Ciencias Sociales, Universidad de la República, 2006). Elma Montaña et al., "Los espacios invisibles. Subordinación, marginalidad y exclusión de los territorios no irrigados en las tierras secas de Mendoza, Argentina", Región y Sociedad 32 (2005): 3-32. Laura Torres, "Hilos de agua, lazos de sangre: enfrentando la escasez en el desierto de Lavalle (Mendoza, " Argentina)", Ecosistemas 17, no 1 (2008), http://www.revistaecosistemas.net/index.php/ecosistemas/article/view/110. 